\title{
Activity of Wnt-1 as a transmembrane protein
}

\author{
Neil T. Parkin, ${ }^{1,4,5}$ Jan Kitajewski, ${ }^{2}$ and Harold E. Varmus ${ }^{1,3}$ \\ ${ }^{1}$ Departments of Microbiology and Immunology and ${ }^{3}$ Biochemistry and Biophysics, University of California, San Francisco, \\ San Francisco, California 94143-0502 USA; ${ }^{2}$ Department of Pathology in the Center for Reproductive Sciences, College \\ of Physicians and Surgeons, Columbia University, New York, New York 10032 USA
}

The product of the Wnt-1 proto-oncogene is a cysteine-rich glycoprotein that plays a crucial role in the development of the vertebrate central nervous system. Wnt-1 protein is secreted but remains associated with the cell surface and extracellular matrix. The function of Wnt-1 in several different biological settings can be carried out by cells that receive the Wnt signal from adjacent cells. Ectopic expression of Wnt-1 in certain mammary gland cell lines, such as C57MG, causes morphological transformation; C57MG cells can also be transformed by a paracrine mechanism when mixed with other cell types secreting Wnt-1 protein. To ask whether Wnt-1 protein can function while bound to the cell of origin, a variety of cell types were programmed to produce chimeric proteins containing the complete sequence of mature Wnt-1 protein fused to part or all of the transmembrane protein CD4 or CD8. The chimeras were found at the cell surface of transfected cells and did not appear to be proteolytically processed. In autocrine and paracrine transformation assays with C57MG cells and in an axis induction assay in Xenopus laevis embryos, the Wnt-1/CD4 or CD8 fusions retained significant activity, as did a secreted chimera containing the CD8 extracellular domain but lacking the transmembrane domain. However, a chimera lacking a spacer between the Wnt-1 and the transmembrane domains was weakly active and only in autocrine transformation. These results show that tethering Wnt-1 to the cell surface still allows Wnt-1-mediated cell-to-cell signaling.

[Key Words: Wnt-1; transmembrane protein; transformation; mammary oncogene; CD4; CD8]

Received July 1, 1993; revised version accepted August 31, 1993.

The Wnt-1 proto-oncogene encodes a cysteine-rich, secreted glycoprotein (Fung et al. 1985; Brown et al. 1987; Papkoff et al. 1987) that stimulates growth and morphological transformation in certain mammary gland cell lines (Brown et al. 1986; Rijsewijk et al. 1987) and induces dorsal axis duplication in Xenopus laevis embryos (McMahon and Moon 1989; Kimelman et al. 1992). Initially discovered as a target for activation by integration of mouse mammary tumor virus (Nusse and Varmus 1982; Nusse et al. 1984) and subsequently characterized as a mammary proto-oncogene (Tsukamoto et al. 1988), the Wnt-1 gene is normally required in the mouse for development of the central nervous system (CNS). The normal sites of production of Wnt-1 RNA are restricted to the embryonic brain and spinal cord and postmeiotic spermatids in adults (Shackleford and Varmus 1987; Wilkinson et al. 1987). In mice lacking Wnt-1 the development of the midbrain and cerebellum is severely impaired, resulting in neonatal death or severe ataxia

\footnotetext{
${ }^{4}$ Corresponding author.

${ }^{5}$ Present address: Aviron, 1450 Rollins Road, Burlingame, California 94010 USA.
}

(McMahon and Bradley 1990; Thomas and Capecchi 1990; Thomas et al. 1991). Wnt-1 is the prototype member of a large gene family that includes orthologs in all vertebrates examined and several other organisms (Nusse and Varmus 1992; Sidow 1992). Other components of the Wnt-1 signaling pathway, including its presumed receptor, have yet to be identified.

Analysis of the Drosophila ortholog of Wnt-1, the segment polarity gene wingless $(w g)$, has implicated wg protein in cell-cell communication (Nusse and Varmus 1992). wo is required for the establishment of anteriorposterior polarity in the embryonic segment and acts in a cell nonautonomous fashion; patches of mutant cells can be rescued by wild-type tissue in mosaic flies (Morata and Lawrence 1977; Baker 1988). Genetic and biochemical data indicate that $w g$ acts by signaling to adjacent cells to alter their differentiation program, one aspect of which involves the regulation of engrailed (en) expression (DiNardo et al. 1988; Martinez Arias et al. 1988; Heemskerk et al. 1991; Cumberledge and Krasnow 1993). Recently, wg has also been shown to change the fate of surrounding cells when expressed at ectopic sites in imaginal discs (Struhl and Basler 1993). wg expression 
is limited to a single band of cells in each segment; en expression is regulated in an immediately adjacent band of cells. Immunoelectron microscopy has demonstrated the presence of wg protein inside cells that express en, up to several cells away from the wg-expressing cells (van den Heuvel et al. 1989; González et al. 1991). Genetic analysis of $w g$ transcription strongly suggests that wg acts via a paracrine, rather than autocrine, mechanism (Ingham and Hidalgo 1993).

In $X$. laevis embryos, injection of several different Wnt RNAs (including wg, murine Wnt-1, and Xenopus Wnt$1,3 \mathrm{~A}$, and 8 ) leads to the induction of a new Spemann organizer and formation of a second body axis (Moon 1993). Deletion of the hydrophobic leader sequence or mutation of a critical cysteine residue, C369, inactivates the ability of Wnt-1 to induce a secondary axis (McMahon and Moon 1989). The Wnt-injected cells themselves do not necessarily populate the new organizer region or body axis, indicating that they can act as donors of an inducing signal to surrounding cells. Thus, it has been proposed (Smith and Harland 1991; Sokol et al. 1991) that an endogenous Wnt protein is the signal that emanates from the Nieuwkoop center (Kimelman et al. 1992). It is also possible, however, that the Wnt-expressing cells are induced to secrete secondary factors that are directly responsible for organizing the body plan.

Wnt-1 protein is capable of transforming the morphology of the murine mammary gland cell line C57MG by a paracrine mechanism (Jue et al. 1992; Mason et al. 1992). Wnt-1-expressing cells, such as rat or mouse fibroblasts that show no detectable response themselves, can transform neighboring C57MG cells in coculture experiments. This activity depends on entry of the Wnt-1 protein into the secretory pathway, because deletion of the signal sequence abolishes transforming activity (Mason et al. 1992). The distance over which Wnt-1 may act has been estimated by performing paracrine assays using as donors small colonies of Wnt-1-expressing rat (Jue et al. 1992) or QT6 cells (N. Parkin, J. Kitajewski, and H.E. Varmus, unpubl.). In such experiments, surrounding C57MG cells show morphological transformation in a ring $\sim 5-10$ cells wide.

In cultured cells expressing Wnt-1 ectopically, the majority of Wnt-1 protein is present in the endoplasmic reticulum (ER), where it associates with the immunoglobulin heavy chain-binding protein $\mathrm{BiP}$ (Kitajewski et al. 1992); only a relatively small proportion is actually secreted. Once outside the cell, Wnt-1 protein associates tightly with the cell surface and the extracellular matrix (ECM), where it can be released by incubation with suramin or heparin (Bradley and Brown 1990; Papkoff and Schryver 1990). Such treatment, however, abrogates its activity. Proteins encoded by other members of the Wnt gene family behave in a similar fashion (Blasband et al. 1992; Chakrabarti et al. 1992; J. Kitajewski, N. Parkin, and H.E. Varmus, unpubl.). In this way, the range of action of Wnt protein can be restricted, implying that the Wnt signal may be confined to cells only a short distance away from the donor cell in vivo. Severe defects in segmental patterning are observed when $w g$ is expressed ubiquitously in Drosophila embryos (Noordermeer et al. 1992), implying that restriction of the range of action of wg protein is important for segment polarity.

Thus, the biochemical and genetic properties of Wnt-1 suggest that it is a locally acting growth factor and that mechanisms for restriction of its range of action are inherent in these properties. Another potential mechanism for limiting the range of action of a growth or differentiation factor is its expression as a transmembrane protein. Several other growth factors have been described that can function as transmembrane proteins (Brachmann et al. 1989; Mroczkowski et al. 1989; Wong et al. 1989; Perez et al. 1990; Dobashi and Stern 1991; Krämer et al. 1991; Rebay et al. 1991|. To determine whether or not Wnt-1 can function as a transmembrane rather than a secreted protein, we generated chimeric proteins between Wnt-1 and two transmembrane molecules, CD4 and CD8. The transmembrane fusions are active in transformation assays in C57MG cells and induce a new body axis in $X$. laevis. Although the activity of the chimeras is less than that of wild-type Wnt-1, it is similar to that of a secreted chimera containing only the extracellular domain of CD8. We conclude that conversion of Wnt-1 into a transmembrane protein does not in itself impair biological activity.

\section{Results}

\section{Wnt-1/CD4 and CD8 chimeras}

Two well-characterized transmembrane proteins, CD4 and CD8, were chosen to construct Wnt-1-containing chimeric proteins anchored to cell membranes. These proteins are involved in the $\mathrm{T}$-cell activation response and are thought to interact with major histocompatibility complex (MHC) class I (CD8) or class II (CD4) proteins on the surface of antigen-presenting cells (Janeway 1992). Both CD4 and CD8 are thought to have a rigid, rod-like structure that extends the MHC-binding sites away from the cell membrane. Therefore, the Wnt-l portion of WntCD4 and WntCD8 chimeras should be able to bind to the Wnt-1 receptor on adjacent responsive cells.

Fusions were made to the carboxyl terminus of the Wnt-1 protein, because we have previously added amino acids there without loss of Wnt-1 activity (J. Kitajewski, J. Mason, and H.E. Varmus, unpubl.). The complete Wnt1 -coding sequence was used to preserve the penultimate amino acid, a cysteine at position 369 (C369), known to be critical for Wnt-1 function (McMahon and Moon 1989; Mason et al. 1992). In constructs containing the entire extracellular domain of CD4 or CD8, the junctions are at the predicted signal peptide cleavage sites of the transmembrane protein (e.g., WntCD4, WntCD8, and WntCD8 $\zeta$; see Fig. 1). A shorter construct, containing only a 5-amino-acid spacer between the carboxyl terminus of Wnt-1 and the transmembrane domain of CD4, was also made (Wnt $\Delta C D 4$ ). To examine possible effects of the extracellular domain of CD8 on the activity of Wnt-1, a secreted fusion lacking the transmembrane and cytoplasmic sequences (sWntCD8) was created by intro- 


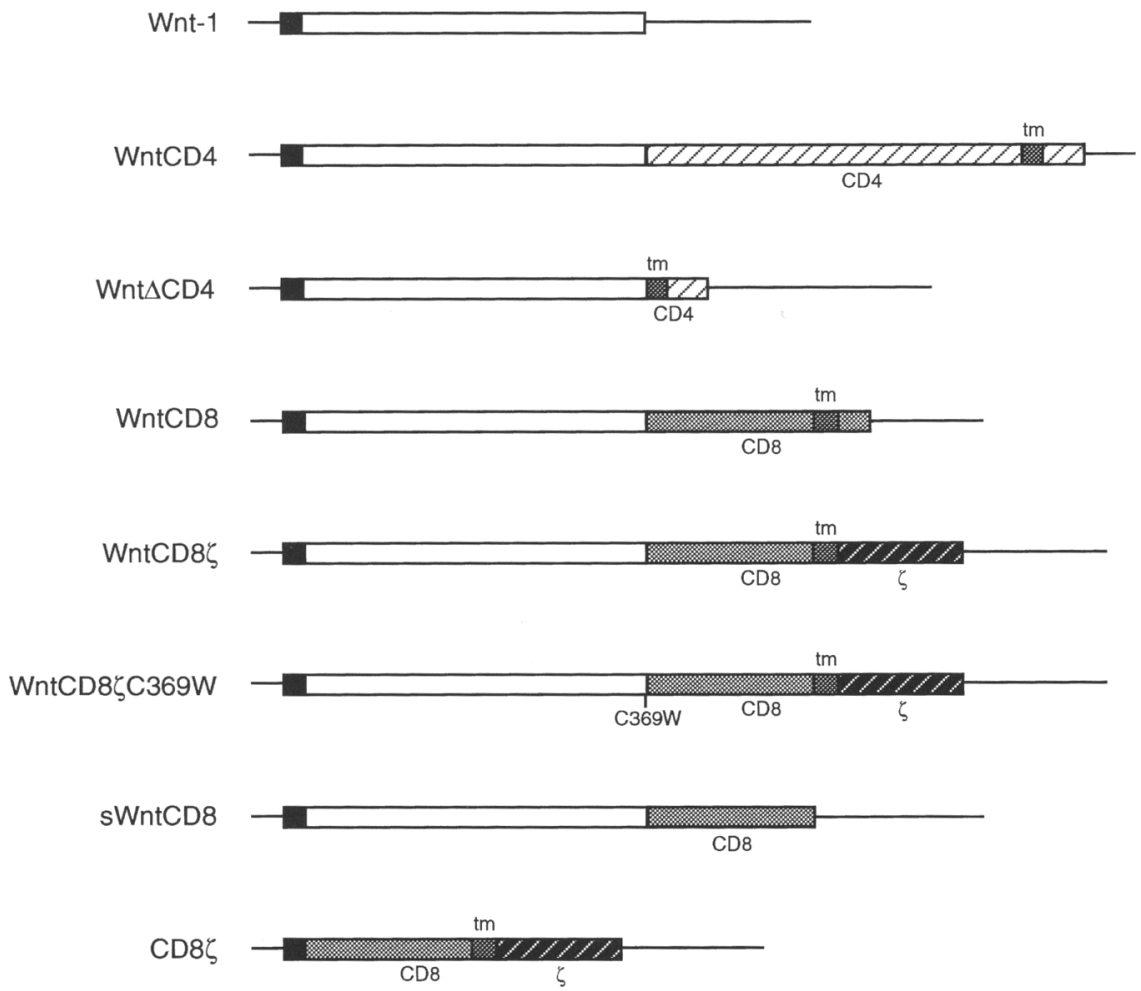

Figure 1. A schematic representation of Wnt- 1 and derived transmembrane chimeras. Constructs were assembled in pBluescript plasmids and transferred to pLHTCX for generation of recombinant retrovirus stocks or to pSP64T for in vitro transcription. The extracellular domains of CD4 and CD8 are 374 and 161 amino acids in length, respectively. Wnt $\triangle C D 4$ retains only 5 amino acids of the CD4 extracellular domain. For details of construction, see Materials and methods. (tm) Transmembrane domain. The signal peptide is represented by a black box. ducing a stop codon just $5^{\prime}$ of the start of the region encoding the CD8 transmembrane domain. In WntCD8 3 the cytoplasmic portion of CD8 has been exchanged for that of the T-cell receptor signaling molecule, $\zeta$ (Irving and Weiss 1991; Weiss 1993). This chimera was made primarily for other purposes (see Discussion) but serves here as a control for any potential effects of the cytoplasmic portion of the WntCD8 fusion. Also, the inactivating C369W mutation (McMahon and Moon 1989; Mason et al. 1992) was introduced in this background as a negative control.

\section{Expression of Wnt-1/transmembrane chimeras}

The various cDNA constructs were cloned into a retroviral expression vector and introduced into RatBla cells. To ensure that intact fusion proteins were produced and not subsequently cleaved, clones of infected cells were pulse labeled for $1 \mathrm{hr}$ with $\left[{ }^{35} \mathrm{~S}\right]$ cysteine and incubated for $4 \mathrm{hr}$ in medium containing excess unlabeled cysteine and $1 \mathrm{~mm}$ suramin /suramin is required to immunoprecipitate secreted Wnt-1 protein from the medium of expressing cells; Papkoff and Schryver 1990). As shown in Figure 2, only Wnt-1 and sWntCD8 could be detected in the medium after the chase. The apparent secretion efficiency of Wnt-l is high in this cell line; however, this type of analysis tends to exaggerate the relative amount of labeled protein outside the cell, because the half-life of extracellular Wnt-1 protein is longer (Bradley and Brown 1990; Papkoff and Schryver 1990). The amount of sWntCD8 protein detected in the medium after the chase was $\sim 15$-fold lower (accounting for differences in cysteine content) than the amount of Wnt-1 protein. This may be the result of reduced secretion efficiency, a shorter extracellular half-life of this protein, or both. The sWntCD8 proteins found in the medium migrate significantly more slowly than the intracellular forms, and the shift in mobility is greater than that seen for Wnt-1. This effect is likely the result of $\mathrm{O}$-linked glycosylation on the CD8 portion of the chimera (Snow et al. 1984). Importantly, after exposure of the autoradiograph for 4 days (Fig. 2), no Wnt-containing cleavage products could be detected in medium from any of the cell lines expressing the Wnt-1/transmembrane chimeras. After a 26-day exposure 40 times the minimum exposure needed to detect the sWntCD8 band), there were still no potential cleavage products visible; at this level of sensitivity, we would thus expect to be able to detect levels of Wnt-1containing proteins as low as 40 -fold below that of sWntCD8. After this long exposure, a faint band was visible in the last lane of the gel, possibly representing intact WntCD4 protein released into the medium in association with cellular debris. Scintillation counting of this region of the dried gel suggested that it represented at least 80-fold less protein than sWntCD8 (data not shown). This low level of protein in the medium can be considered insignificant in the context of the activity assays used (see below).

Wnt-1/transmembrane chimeras are expressed at the cell surface

To ensure that the transmembrane Wnt fusions were transported to the cell surface, RatBla cell lines express- 
Figure 2. Expression of Wnt-1/transmembrane chimeras in RatBla cells. Clonal cell lines of RatBla were generated and labeled with $\left[{ }^{35}\right.$ S $]$ cysteine for $1 \mathrm{hr}$ and chased for $4 \mathrm{hr}$ in complete medium containing $1 \mathrm{~mm}$ suramin. The chase medium or cell lysates were immunoprecipitated with anti-Wnt-1 monoclonal antibody and analyzed by electrophoresis and fluorography. Exposure times for the lysates (left) and chase medium (right) were $16 \mathrm{hr}$ and 4 days, respectively.

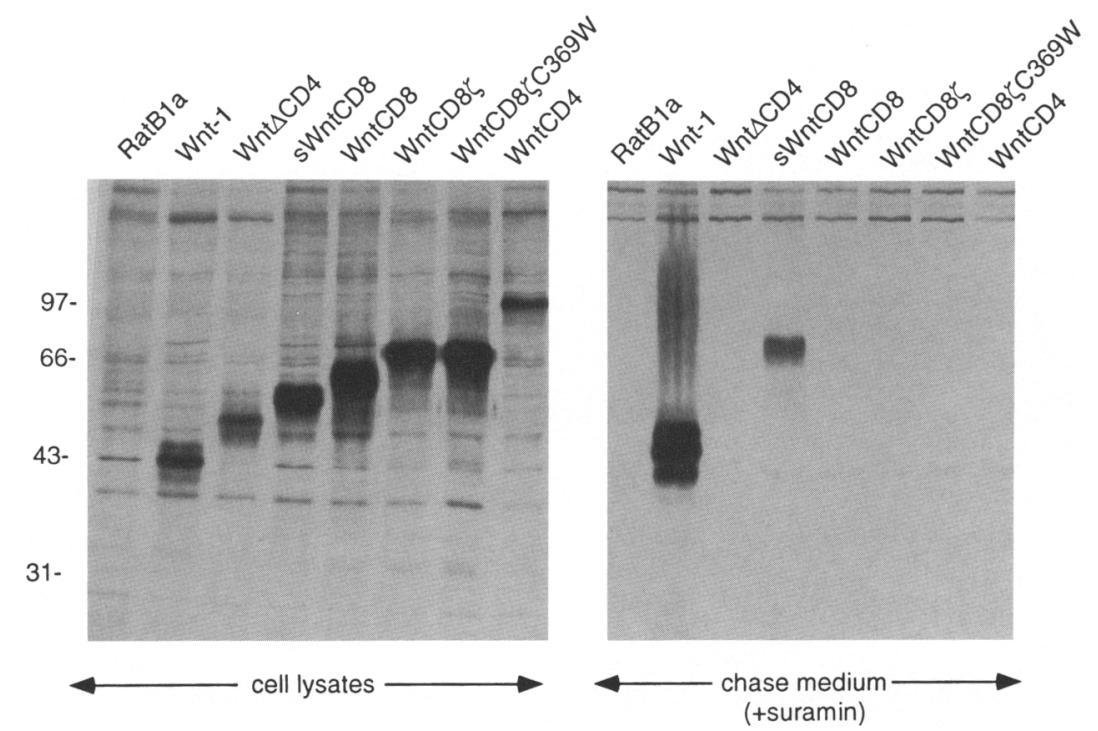

ing the recombinant proteins were subjected to flow cytometry using fluorescently labeled monoclonal antibodies against CD4 or CD8. As shown in Figure 3, RatBla

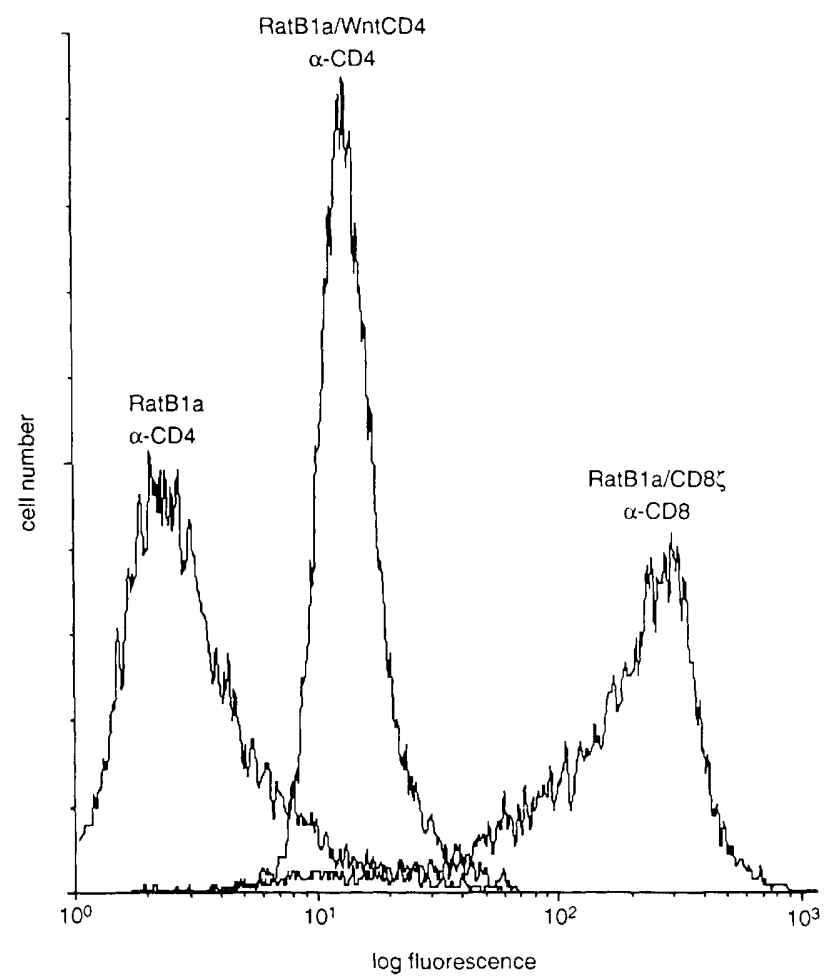

Figure 3. Flow cytometry analysis of cells expressing WntCD4. Dissociated RatBla and RatBla/WntCD4 cells were stained with phycoerythrin-labeled anti-CD4 antibody (Leu3a$\mathrm{PE} \mid$ and analyzed by flow cytometry. RatBla cells producing $\mathrm{CD} 8 \zeta$, stained with fluorescein isothiocyanate-labeled antiCD8 (Leu2a-FITC), are shown as a positive control. The background tracings for RatBla cells stained with Leu2a or Leu3a were superimposable; only the latter is shown. cells expressing the WntCD4 chimera were significantly more fluorescent than parental RatB1a cells after addition of anti-CD4 antibody. The increase in fluorescence was not as great as that seen with RatBla cells expressing a control transmembrane protein, $\mathrm{CD} 8 \zeta$ (Irving and Weiss 1991), stained with anti-CD8 antibody. If the relative levels of expression of the two proteins are equal, this observation suggests that transport of WntCD4 to the cell surface is relatively inefficient, as is secretion of wild-type Wnt-1 (Papkoff and Schryver 1990). Staining of cells expressing WntCD8 or WntCD8 $\zeta$ with anti-CD8 did not result in a significant increase in fluorescence, partly because the antibody reacts poorly with the chimeras (the epitope recognized by the Leu2a monoclonal antibody may be partially masked), and partly because these chimeras are less efficiently transported to the cell surface (see below).

We then used indirect immunofluorescence methods to examine the appearance of chimeric proteins on the cell surface in more detail and to compare cells expressing the chimeric proteins with those expressing wildtype Wnt-1. Uninfected RatBl a cells or clones expressing the various constructs were plated on fibronectin-coated coverslips and stained, unfixed and unpermeablized, with anti-Wnt monoclonal antibody (Fig. 4). In wild-type Wnt-1-expressing cells, Wnt-1 protein was detected on the extracellular matrix surrounding the cells, with some staining also seen over their surface (Fig. 4A,B). In contrast, RatBla cells expressing Wnt $\Delta C D 4$ (Fig. 4C,D), WntCD4 (E,F), WntCD8 (G,H), or WntCD8 (not shown) showed a different type of staining. The observable staining was confined to the cell surface, implying little or no association with the ECM. Although the sensitivity of this procedure might not be sufficient to detect small amounts of secreted or cleaved WntCD4 or WntCD8 protein, when taken together with the immunoprecipitation analysis (Fig. 2) the data strongly indicate that the fusion proteins are confined to the cell surface. Cells 
IF
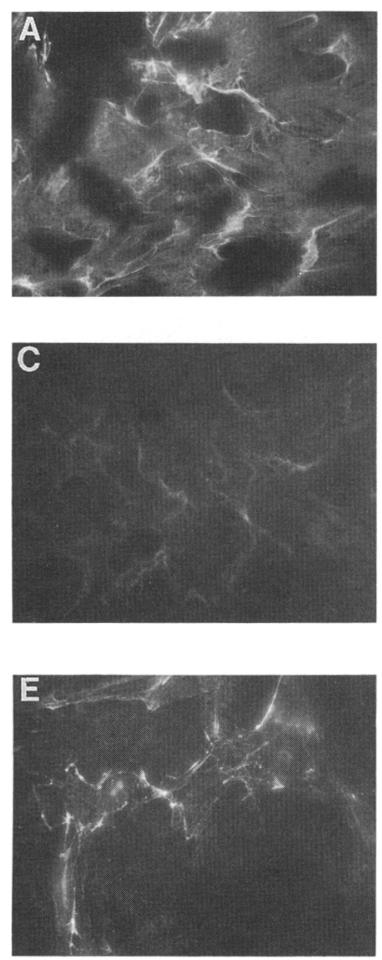

PHASE
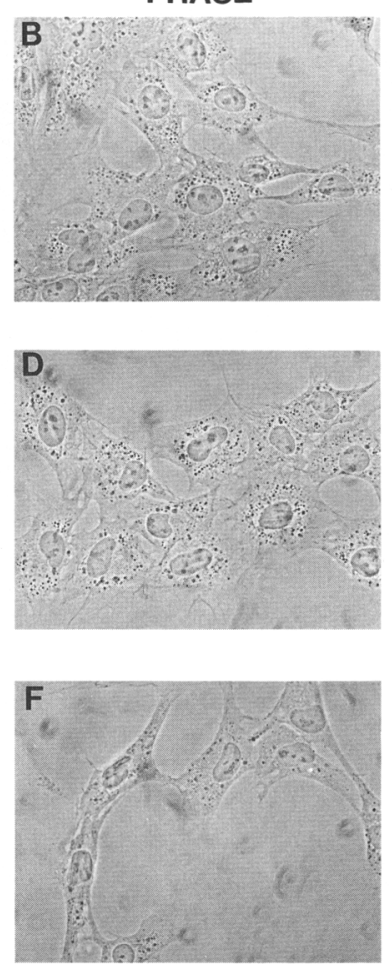

IF
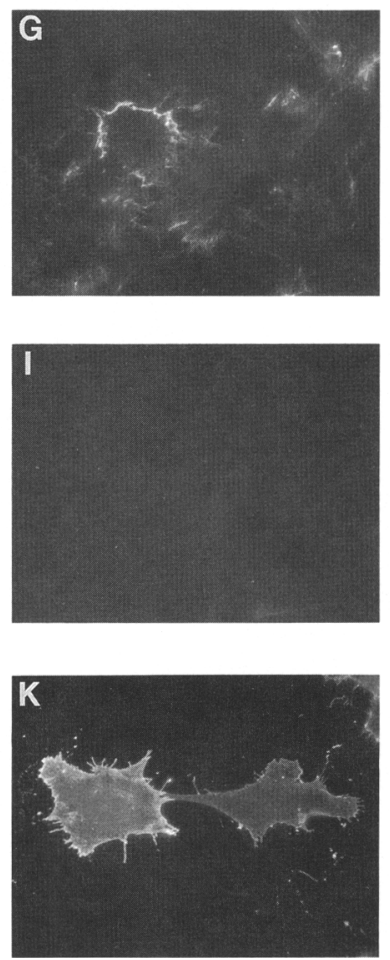

PHASE
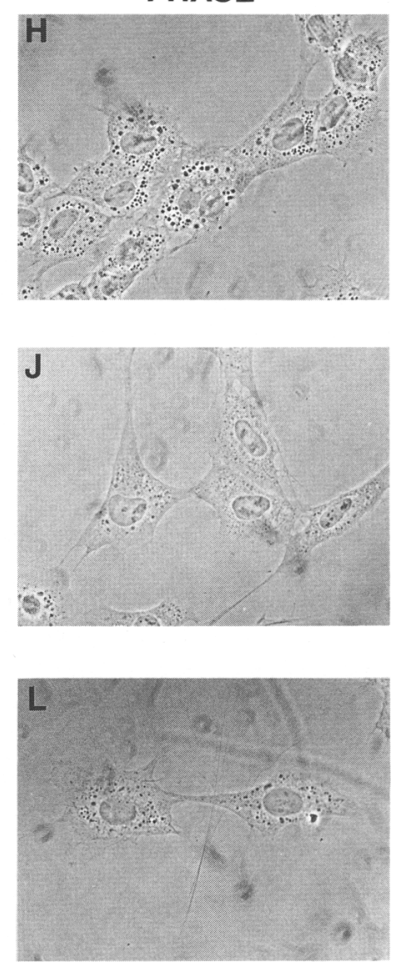

Figure 4. Immunofluorescence analysis of cells expressing chimeric Wnt-1/transmembrane proteins. Uninfected RatBla cells $(I, /)$ or clones expressing Wnt-1 $(A, B)$, Wnt $\Delta C D 4\{C, D\}$, WntCD4 $\{E, F\}$, WntCD8 $\{G, H\rangle$ or CD8 $\zeta(K, L)$ were plated on fibronectin-coated coverslips and incubated with anti-Wnt- $\mid(A-I)$ or anti-CD8 $(\mathrm{OKT} 8)(K, L)$ monoclonal antibodies, followed by staining with Texas Red-conjugated anti-mouse IgG. Cells were photographed using Kodak Tri-X film at a magnification of $\sim 500 \times$. Immunofluorescence (IF) is shown on the left $(A, C, E, G, I, K)$, and the corresponding phase contrast field (PHASE) is on the right $(B, D, F, H, J, L)$.

expressing WntCD4 reproducibly gave the strongest signal, suggesting that the WntCD4 protein was the one most efficiently transported to the surface in this cell type. The low intensity of staining seen for Wnt $\Delta C D 4$ is the result, in part, of a lower level of expression in this clone (see Fig. 2). Very low background staining was observed with parental RatBla cells $(\mathrm{I}, J)$. An intense pattern typical for abundant cell surface proteins was found after the staining of RatBla cells producing $\mathrm{CD} 8 \zeta$ with antiCD8 antibody $(\mathrm{K}, \mathrm{L})$.

\section{Activity of Wnt-1/transmembrane chimeras in C57MG cells}

To test the chimeric transmembrane proteins for transforming activity, the recombinant constructs were introduced into the Wnt-1-responsive mammary gland cell line C57MG (Table 1; Fig. 5). As production of Wnt-1 protein in this cell line after retrovirus infection is somewhat unstable (Mason et al. 1992), all lines used to assay morphological changes were monitored for Wnt-1 protein by immunoblotting (Fig. 5; data not shown). Uninfected C57MG cells exhibit a flat, cuboidal type of morphology (Fig. 5A). As described previously (Brown et al. 1986), when C57MG cells produce Wnt-1, they are trans-
Table 1. Activity of Wnt-1/transmembrane chimeras in C57MG cells

\begin{tabular}{lcc}
\hline & \multicolumn{2}{c}{ Activity $^{\mathbf{a}}$} \\
\cline { 2 - 3 } Construct & autocrine & paracrine \\
\hline Wnt-1 & +++ & +++ \\
C369W & - & - \\
Wnt $\Delta$ CD4 & + - & - \\
WntCD4 & + & + \\
WntCD8 & + & + \\
WntCD85 & + & + \\
WntCD85-C369W & - & - \\
sWntCD8 & + & + \\
CD85 & - & - \\
\hline
\end{tabular}

${ }^{a}$ For determination of autocrine activity, pools of C57MG cells producing the indicated protein were plated in $60-\mathrm{mm}$ petri dishes; the medium was changed to $\mathrm{HB}-\mathrm{CHO}$ at subconfluence, and the morphology was assessed 2 days later (see Materials and methods). For paracrine assays, clones of RatBla cells producing the chimeras were cocultured with C57MG cells at an equal ratio; again the medium was changed to $\mathrm{HB}-\mathrm{CHO}$ at subconfluence. The degree of morphological transformation is indicated as follows: $(-\mid$ Not detectable (e.g., Fig. 5A); $(+/-)$ weak but detectable (Fig. 5D $)_{i}(+)$ intermediate (e.g., Fig. $\left.5 \mathrm{C}\right)_{i}(+++)$ morphology of wild-type Wnt-l-transformed C57MG cells (Fig. $5 B)$. 
Figure 5. Autocrine transformation assays in C57MG cells. Uninfected C57MG cells $|A|$ or C57MG cell lines expressing Wnt-1 $(B)$, WntCD8 $\zeta|C|$, or Wnt $\Delta C D 4$ $(D, E)$ were plated at subconfluent densities. The medium was then changed to HB$\mathrm{CHO}$; cells were photographed 2 days later at a magnification of $200 \times$ (see Materials and methods). A C57MG cell line infected with a recombinant virus construct intended to express an unrelated Wnt-1 fusion protein, but which did not produce detectable levels of it, is shown for comparison (control, F). The immunoblot at bottom displays the relative amounts of Wnt proteins in the indicated cell lines.

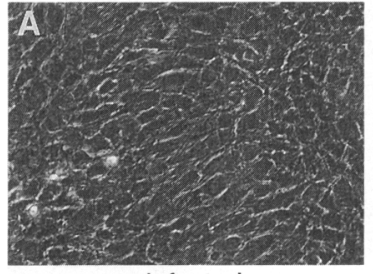

uninfected
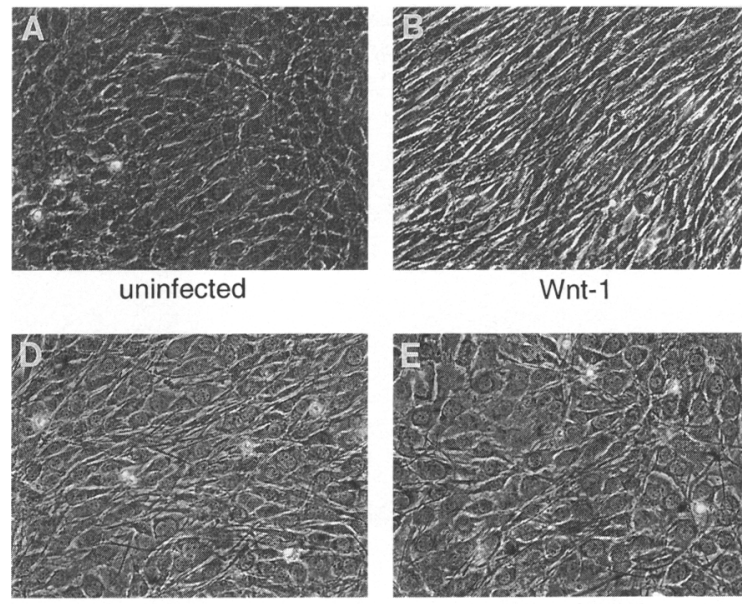

Wnt $\triangle$ CD4-1
Wnt-1

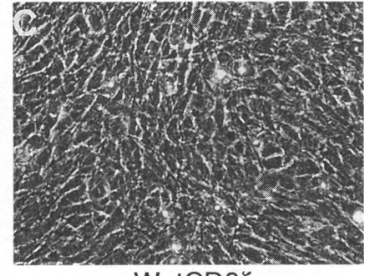

WntCD8 $\zeta$
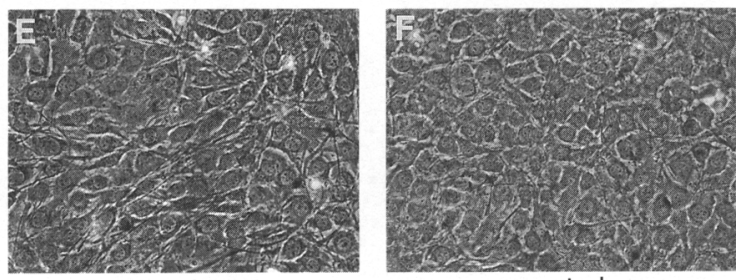

control formed into elongated, refractile, fibroblast-like cells (B). C57MG cells making WntCD8 $\zeta(C), W n t C D 4$, or WntCD8 (data not shown) showed an intermediate type of morphology, implying that the chimeric proteins are active but less potent than wild-type Wnt-1. A similar morphology was seen with C57MG cells expressing sWntCD8 (not shown). This indicates that the reduction in activity seen with WntCD8 is the result of an effect of the carboxy-terminal CD8 portion of the chimera rather than a direct consequence of the attachment of Wnt- 1 to the cell surface. Alternatively, the attenuation of activity may result, in part, from a reduction in efficiency of transport of WntCD8 to the cell surface relative to the efficiency of secretion of Wnt-l protein, because sWntCD8 is secreted less efficiently than Wnt-1 (see Fig. 2). The partial transformation induced by these chimeras was not observed with WntCD8 $3 \mathrm{C} 369 \mathrm{~W}$, a chimera containing an inactivating mutation.

C57MG cells expressing the short Wnt $\triangle C D 4$ construct showed a very subtle but reproducible change in morphology; two independent examples are shown (Fig. $5 \mathrm{D}, \mathrm{E})$. The cells were not markedly elongated, but they extended processes and were slightly more refractile than controls. Only cell lines in which the fusion protein could be detected by immunoblotting (Fig. 5, bottom) showed the morphological changes. A C57MG cell line that failed to express a different Wnt fusion gene showed no alteration in phenotype and provided an independent control $(\mathrm{F})$.

\section{Wnt-1/transmembrane chimeras can transform C57MG cells by a paracrine mechanism}

The activity of the chimeras in C57MG cells could be the result of the interaction of the Wnt-1 portion with its receptor in the ER of the expressing cells, on the surface of expressing cells, on the surface of adjacent cells, or a combination of these possibilities. To determine whether the chimeric proteins could also transform C57MG cells strictly by a paracrine route, RatBla cell lines expressing the chimeric proteins were cocultured with C57MG cells in an approximately equal ratio. The findings (summarized in Table 1 and illustrated in Fig. 6) were very similar to those obtained by introducing the chimeric constructs directly into C57MG cells (see above). Although coculture of C57MG and parental RatBla cells did not result in the transformation of the C57MG cells (Fig. 6A), mixing with RatBla cells producing Wnt-1 led to a change in morphology indistinguishable from that seen when Wnt-1 was expressed directly in the C57MG cells (cf. Figs. 5B and 6B; the donor cells are not visible because of overgrowth of the C57MG monolayer). Coculture of C57MG cells with RatBla clones producing WntCD8 $\zeta$ (Fig. 6C), WntCD8, sWntCD8, or WntCD4 (data not shown) resulted in an intermediate transformation, which was not seen with clones making the WntCD $8 \zeta \mathrm{C} 369 \mathrm{~W}$ control chimera (D). The short Wnt $\Delta C D 4$ protein, however, did not show paracrine transforming activity (not shown). Possible explanations for this observation are presented in the Discussion.

\section{Activity of Wnt-1/transmembrane chimeras in Xenopus embryos}

We then asked whether the Wnt-1 fusion proteins tethered to the cell surface are able to induce a new dorsal axis in $X$. laevis embryos. RNAs encoding Wnt- 1 or the various chimeras were injected into embryos at the two- 


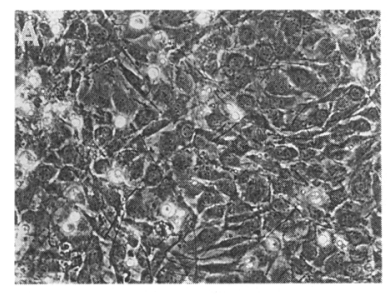

uninfected

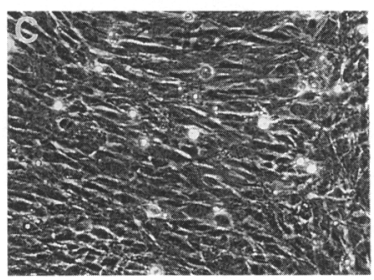

WntCD8C

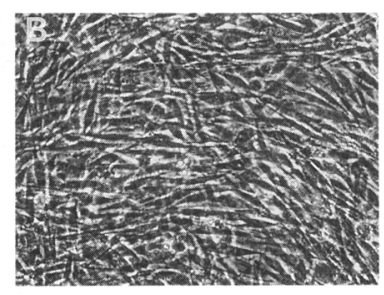

Wnt-1

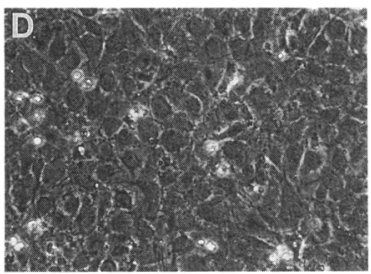

WntCD8ל-C369W
Figure 6. Paracrine transformation assays in C57MG cells. Uninfected RatBla cells $|A|$ or clones expressing Wnt-1 $|B|$, WntCD8 $\zeta(C)$, or WntCD83C369W $(D)$ were mixed with an equal number of C57MG cells; pictures were taken 2 days after the medium was changed to $\mathrm{HB}-\mathrm{CHO}$ (see Materials and methods).

cell stage, and surviving embryos were monitored for appearance of a new body axis at neurula and tailbud stages (Table 2; Fig. 7). Examination at the latter stage was important because partial bifurcations (e.g., expanded cement glands or bifurcations that did not develop anterior structures) were more obvious than at the neurula stage. For the purpose of scoring Wnt activity, partial and complete bifurcations were grouped together and are referred to as "affected".

Ten picograms of Wnt-1 RNA induced clear bifurcations and/or severe dorsoanteriorization in nearly $100 \%$ of injected embryos (Fig. 7A; some examples of clear bifurcations are indicated by arrowheads). Activity was detectable at doses as low as $1 \mathrm{pg}$, in agreement with a previous report (Sokol et al. 1991). WntCD4 (Fig. 7B), WntCD8 (C), WntCD8\% (not shown), and sWntCD8 (D) RNAs all showed approximately equal activity, requiring $250 \mathrm{pg}$ per blastomere to affect $55-80 \%$ of the embryos. The full range of phenotypes, including complete bifurcation identical to that seen for wild-type Wnt-1, was observed for all of these RNAs. Again, the WntCD8 3 C369W mutant showed no activity (not shown). Embryos injected with Wnt $\Delta C D 4$ RNA (Fig. 7E) or with Wnt-1 C369W mutant RNA (not shown) never developed signs of secondary axes, even at doses of 500 pg to $1 \mathrm{ng}$. All RNAs used for these microinjection experiments produced proteins of only the expected size and in equal amounts when translated in Xenopus oocytes (data not shown).

\section{Discussion}

The results presented in this report demonstrate that
Wnt- 1 is active when it is produced as a transmembrane protein. The WntCD4 and WntCD8 chimeric proteins were able to elicit partial morphological transformation in C57MG cells either by direct expression or by a paracrine route after coculture with donor RatBla cells producing the chimeras. Paracrine transformation was not observed with a chimeric protein lacking the extracellular domain of CD4, suggesting the need for a spacer between Wnt-1 and the transmembrane domain / see below). The transmembrane Wnt-l chimeric proteins were also able to induce a new dorsal axis in $X$. laevis embryos. Once again, there was a requirement for a spacer domain. The reduction in activity observed when Wnt-l is fused to a transmembrane protein is the result of the addition of new sequences to the carboxyl terminus, because a secreted chimera containing the extracellular domain of CD8 was similarly attenuated. This effect of adding extra amino acids to the carboxyl terminus of Wnt-l has also been observed in at least one other case, after addition of an influenza hemagglutinin epitope tag (J. Kitajewski and H.E. Varmus, unpubl.).

The Wnt $\Delta C D 4$ chimera has no paracrine activity but has partial transforming activity when expressed directly in C57 cells. This observation could be explained by a requirement for a spacer between the transmembrane and Wnt-1 domains to reach the receptor on the adjacent C57MG cells. Autocrine transformation would then be a result of Wnt-1 binding to its receptor in the ER or on the surface of expressing cells, which presumably does not require the spacer domain. Alternatively, the conformation of Wnt-1 could be affected differently by the carboxy-terminal sequences of this chimera in the extracellular environment; hence, it might retain activity only in the ER. Another possible explanation is that paracrine

Table 2. Activity of Wnt-1/transmembrane chimeras in Xenopus embryos

\begin{tabular}{lccr}
\hline & \multicolumn{3}{c}{$\begin{array}{c}\text { Percentage of injected embryos showing } \\
\text { a secondary axis }\end{array}$} \\
\cline { 2 - 4 } RNA & $10 \mathrm{pg}$ & $50 \mathrm{pg}$ & $250 \mathrm{pg}$ \\
\hline Wnt-1 & $96^{\mathrm{b}}(71)$ & $100^{\mathrm{b}}(18)$ & \\
C369W & & & $0^{\mathrm{c}}(75)$ \\
Wnt $\Delta$ CD4 & $52(25)$ & $0^{\mathrm{c}}(71)$ \\
WntCD4 & $28(36)$ & $87(23)$ \\
WntCD8 & $57(92)$ & $0(54)$ \\
WntCD85 & $38(79)$ & $55(31)$ \\
WntCD85-C369W & & & $0(20)$ \\
sWntCD8 & & & \\
CD85 & & &
\end{tabular}

${ }^{a}$ Xenopus embryos were injected with the indicated dose of RNA and allowed to develop to the tailbud stage, when the number of embryos showing signs of dorsal axis duplication was determined. No duplications were observed following injection of water only (see Fig. 7).

${ }^{b}$ More drastic dorsalizing effects, in addition to axis duplication, are seen at these doses of Wnt-1 RNA.

${ }^{\mathrm{c}}$ Higher doses $(0.5-1 \mathrm{ng})$ have also been tested, still with no effect. 


\section{Parkin et al.}

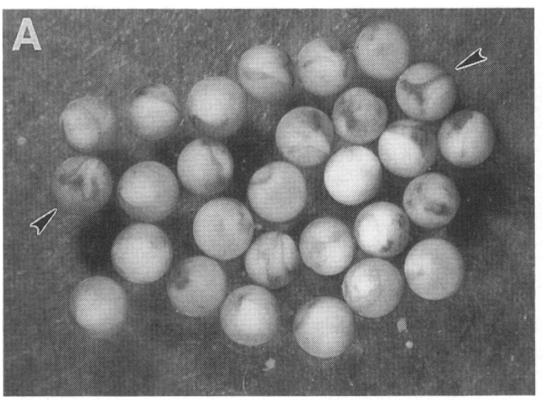

Wnt-1 (10 pg)

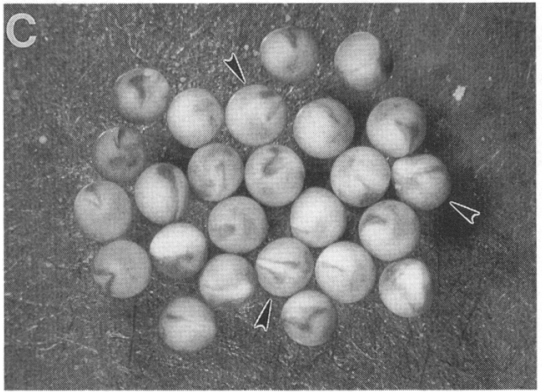

WntCD8 (250 pg)

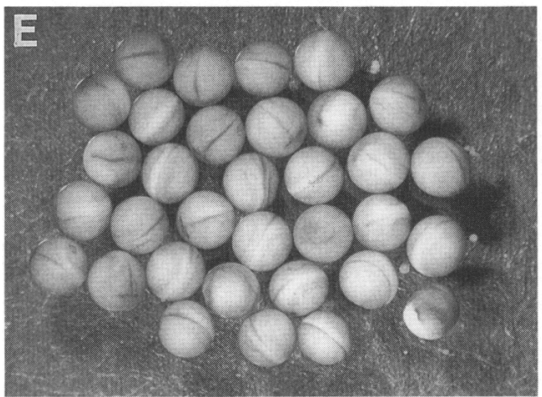

Wnt $\Delta$ CD4 (500 pg)

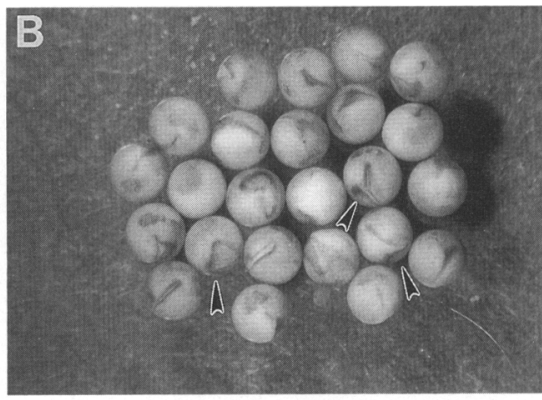

WntCD4 (250 pg)

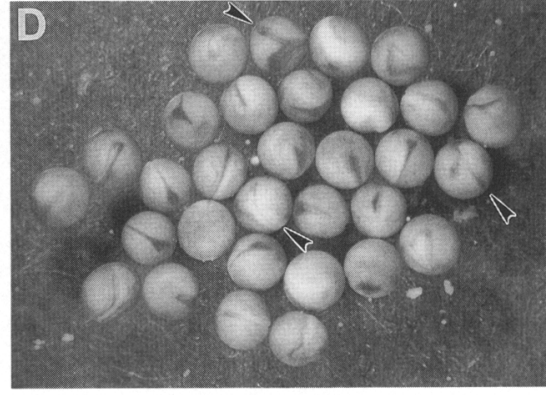

sWntCD8 (250 pg)

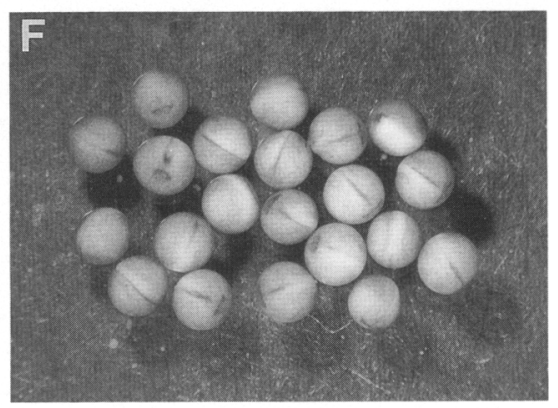

$\mathrm{H}_{2} \mathrm{O}$ bifurcated axes are indicated by arrowheads in $A-D$.

Figure 7. X. laevis axis bifurcation assay. Representative groups of neurulas /stage 20) are shown that were injected with RNAs encoding Wnt- $1(10 \mathrm{pg}, A)$, WntCD4 $(250 \mathrm{pg}, B)$, WntCD8 (250 pg, C), sWntCD8 $(250 \mathrm{pg}, D)$, Wnt $\Delta \mathrm{CD} 4(500 \mathrm{pg}, E)$, or with water $\langle F\rangle$. Clear examples of neurulas with transformation by Wnt $\Delta C D 4$ requires a much higher level of cell surface expression. Because this protein also lacks activity in the Xenopus assay, it is tempting to speculate that axis duplication depends on paracrine signaling. One testable predication of this hypothesis is that retention of Wnt-1 in the ER of expressing cells should abrogate its paracrine and axis-inducing activity. Previously, we have attempted to do this by attaching the ER retention signal KDEL (Pelham 1990) to the carboxyl terminus of Wnt-1. However, the Wnt-1/KDEL protein was not retained and was as active as wild-type Wnt-l (J. Mason, J. Kitajewski, and H.E. Varmus, unpubl.), implying that it adopts a conformation that prevents recognition of the KDEL motif by its receptor in the ER.

The WntCD4 and WntCD8 chimeras were expressed intact in transfected cells and in Xenopus oocytes, indicating that their activity is not attributable to a diffusible cleavage product that migrates away from expressing cells. However, we cannot rule out the remote possibility that a very low level of cleavage does occur, generating an undetectable amount of free Wnt-1 protein. We consider this possibility unlikely, as extended exposure of autoradiographs, such as that shown in Figure 2, did not reveal such cleavage products in the medium, even when we would have detected levels far below the levels of Wnt-1 protein and at least 40-fold lower than those of sWntCD8. It is formally possible, however, that undetected amounts of cleavage products are above a threshold required for activity. To fully explain our results in this way, it is also necessary to postulate that the cleavage products would have a much higher specific activity than the intact chimeras. This scenario is extremely unlikely, as all alterations made to the Wnt-1 protein so far have either not affected its activity or attenuated it (McMahon and Moon 1989; Mason et al. 1992; N.T. Parkin, J. Kitajewski, and H.E. Varmus, unpubl.); a version of Wnt-1 with greater than wild-type activity has never been observed.

Wnt-1 protein has been postulated to be associated with both the cell surface (Papkoff and Schryver 1990) and the ECM (Bradley and Brown 1990). Our immuno- 
fluorescence analysis confirms that this is the case, at least for RatBla cells (Fig. 4) or QT6 cells (N.T. Parkin and H.E. Varmus, unpubl.) grown on glass coverslips. The activity of Wnt-1, when it is tethered to the cell surface by a linked transmembrane domain, demonstrates that cell surface-associated Wnt-1 is active. To determine whether ECM-bound Wnt-1 is active, Wnt-1producing cells were removed from the matrix by treatment with EDTA. This treatment leaves most, if not all, of the Wnt-1 protein on the ECM on the dish, as determined biochemically (Bradley and Brown 1990) or by immunofluorescence (N.T. Parkin and H.E. Varmus, unpubl.). C57MG cells were then plated on this ECM; no changes in morphology were induced, suggesting that ECM-bound Wnt-1 may not be active (N.T. Parkin, I. Kitajewski, and H.E. Varmus, unpubl.; A.M.C. Brown, pers. comm.). However, several other models involving a requirement for ECM binding cannot be eliminated, such as the need for transient matrix association during presentation to the Wnt receptor, or for manifestations of Wnt-1 activity that are not tested by the C57 transformation assay.

Several other growth factors are active in the form of transmembrane proteins. The Drosophila developmental regulators encoded by Delta (Rebay et al. 1991) and bride of sevenless (boss) (Krämer et al. 1991) appear to be expressed solely as transmembrane proteins. Interestingly, in the case of boss, it has been demonstrated that the entire transmembrane protein is internalized by sevenless-expressing cells (Cagan et al. 1992). A similar mechanism may be involved in signaling by the Wnt-1/ transmembrane chimeras. Other factors, including epidermal growth factor (EGF) (Mroczkowski et al. 1988), transforming growth factor- $\alpha$ (TGF- $\alpha$ ) (Bringman et al. 1987), tumor necrosis factor (TNF) (Kriegler et al. 1988), colony-stimulating factor 1 (Rettenmier and Roussel 1988), and neu differentiation factor (Wen et al. 1992), are synthesized as transmembrane precursors that are subsequently processed to yield a soluble form of the factor. The intact precursors for EGF (Mroczkowski et al. 1989) and TGF- $\alpha$ (Brachmann et al. 1989; Wong et al. 1989) are active, as are engineered forms of both TNF and EGF, which are surface bound and not cleaved (Perez et al. 1990; Dobashi and Stern 1991). In these cases, intercellular signaling occurs despite the lack of large spacer domains separating the presumed receptor-binding epitopes from the membrane, which is required for paracrine activity of WntCD4. The c-kit ligand, Steel, is also made as a transmembrane precursor /Flanagan and Leder 1990); mutations that prevent expression of this precursor, but still allow production of active, soluble ligand, induce severe developmental defects, suggesting that the membrane-bound form of Steel has unique functions (Brannan et al. 1991; Flanagan et al. 1991).

Thus, there is a large group of growth factors whose range of action can be limited by expression as a transmembrane protein. Still others are bound to ECM components (Rathjen et al. 1990). The extent of diffusion of Wnt-1 in vivo is probably restricted by its association with the cell surface and/or the ECM. This is presum- ably an important mechanism for restricting the effects of Wnt-1 to a very limited set of responsive cells. The studies presented in this report show that production of Wnt- 1 as chimeric transmembrane proteins does not impair its activity when compared with a secreted fusion protein, and thus membrane-bound Wnt-1 may mimic the normal range of action of Wnt-1 in vivo. One way to establish that cell-associated Wnt-1 protein is sufficient for biological function would be to rescue the mutant phenotype of Wnt-1-deficient mice by appropriate expression of the Wnt-1/transmembrane chimeras in vivo.

The surface expression and activity of WntCD4 and WntCD8 $\zeta$ suggest that it may be possible to utilize these chimeras to seek Wnt-1-binding proteins, possibly including its receptor. WntCD8 $\zeta$ was initially constructed with this possibility in mind, as it has been shown that binding of antibodies to CD8 $\zeta$ at the surface of $T$ cells activates all of the signaling pathways involved in the $\mathrm{T}$-cell activation response, including transcription of the interleukin-2 (IL-2) gene (Irving and Weiss 1991). In this way, expression of the WntCD8 $\zeta$ chimera in T cells, followed by binding by anti-Wnt- 1 antibody or by the Wnt receptor, might induce IL- 2 secretion. Similarly, because the cytoplasmic domain of CD4 is sufficient for lck association (Shaw et al. 1989), the activity of this kinase might also be used to assay for functional interactions with the Wnt-1 domain. In QT6 cells cotransfected with lck and WntCD4 expression constructs, WntCD4 is able to associate with lck (N. Parkin and H.E. Varmus, unpubl.). This approach could conceivably be used to clone the Wnt receptor cDNA from an expression library.

\section{Materials and methods}

Construction of Wnt-1/transmembrane chimeras

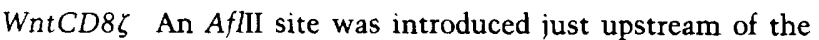
predicted signal peptide cleavage site of CD8 $\zeta$ (Irving and Weiss 1991) by site-directed mutagenesis (Kunkel et al. 1987) in a Bluescript plasmid [pBSKS|+|, Stratagene]. The mutagenic oligonucleotide $15^{\prime}-\mathrm{C}$ CAC GCC GCC AGC TTA AGC CAG TTC CGG-3' (nucleotides in boldface type represent the mutations, and the reading frame is indicated by the triplet spacing)l was designed so that the AfIII site corresponded with respect to the reading frame with an $A$ flII site present at the carboxyl terminus of a mutant Wnt-1 cDNA (Wnt-1/AflII, constructed by J. Mason, University of California, San Francisco; oligonucleotide sequence: 5'-G CAC GAG TGC TTA AGA GGT G-3'). The two mutated cDNAs were then recombined at the introduced $A$ flII sites to give WntCD85. Amino acid 369 of Wnt-1 was mutated to tryptophan in the WntCD8 $\zeta$ chimera (mutagenic oligonucleotide: 5'-G CAC GAG TGG TTA AGC CAG-3') to give WntCD8 3 C369W.

WntCD8 An Eagl fragment from $\mathrm{pBS} / \mathrm{WntCD} 8 \zeta$, which contains the Wnt-1 cDNA and a portion of the CD8 cDNA, was inserted into a pBS plasmid containing the human CD8 $\alpha$ cDNA (pBS/T8F1.1, obtained from the Littman laboratory, UCSF) digested previously with EagI to remove the $5^{\prime}$ end of the CD8 cDNA.

WntCD4 An AflII site was introduced at the predicted signal peptide cleavage site of human CD4 in pBS/CD4 la gift of Ned Landau, UCSF; mutagenic oligonucleotide: 5'-C CCA GCA 
GCC TTA AGG GGA AAC AAA GTG G-3'). This site was used to fuse the CD4 cDNA to the Wnt-l/AflII cDNA to make WntCD4.

Wnt $\triangle C D 4$ A 351-bp NciI fragment was isolated from the carboxyl terminus of the human CD4 cDNA, corresponding to 5 amino acids ot the juxtamembrane extracellular domain, the membrane- spanning sequence, and the cytoplasmic domain. This fragment was ligated to the Wnt-1/AflII cDNA that had been cleaved with AfIII and filled in with Klenow. The 5' junction was sequenced to confirm that the correct reading frame was maintained.

$s W n t C D 8$ A stop codon was introduced by site-directed mutagenesis (oligonucleotide sequence: 5 '-C GCC TGT GAT TAA TAC ATC TGG GCG-3') at the codon immediately preceding the start of the predicted transmembrane domain of WntCD8 $\zeta$.

For expression in cultured cells, constructs were cloned into the retroviral vector pLHTCX (J. Murphy and H.E. Varmus, unpubl.). This vector was derived from pLNCX (Miller and Rosman 1989 ) by replacing the neomycin resistance-coding sequence with that for a hygromycin-resistance/thymidine $\mathrm{ki}$ nase fusion protein (Lupton et al. 1991). In this vector, the hygroTK protein is expressed from the murine leukemia virus long terminal repeat (MLV LTR), whereas the inserted cDNAs are expressed from the cytomegalovinus (CMV) promoter.

For generation of RNAs for microinjection into Xenopus embryos, constructs were subcloned into the pSP64T vector that contains the $5^{\prime}$ - and $3^{\prime}$-untranslated regions (UTRs) of Xenopus $\beta$-globin (Krieg and Melton 1984). To eliminate possible translational repression by the Wnt-1 $5^{\prime}$ UTR, the NcoI site present at the initiator AUG of the Wnt-1 cDNA was used to clone the chimeras into a pSP64T derivative with an appropriately positioned NcoI site (pSP36T; a gift of E. Amaya and M. Kirschner, University of California, San Franciscol. Use of this vector proved to be essential for detection of the encoded proteins by immunoprecipitation after injection of the RNAs into Xenopus oocytes and metabolic labeling (data not shown).

For constructs that were subjected to site-directed mutagenesis, the portion of the clone transferred to the expression vectors was sequenced to ensure that inapparent second-site mutations were not responsible for changes in activity. Alternatively, two independent clones derived from the mutagenesis procedure were tested; no differences in activity were noticed in these cases.

\section{Cell culture and transfection}

C57MG cells (Vaidya et al. 1978) were grown in Dulbecco's modified Eagle (DME) medium H-2l supplemented with $10 \%$ fetal bovine serum (FBS) and $10 \mu \mathrm{g} / \mathrm{ml}$ of insulin. RatBla cells (Finney and Bishop 1993) were obtained from Robert Finney (Bishop laboratory, UCSF) and grown in DME H-21 with $7.5 \%$ calf serum and $2.5 \%$ FBS. The PA317 retrovirus packaging cell line (Miller and Buttimore 1986) was grown in DME H-21 with $10 \%$ FBS. All cell lines were grown at $37^{\circ} \mathrm{C}$ in $5 \% \mathrm{CO}_{2}$.

Recombinant virus was generated by transiently transfecting PA317 cells with pLHTC constructs by calcium phosphate coprecipitation (Sambrook et al. 1989) and harvesting medium over a 16-hr period 2 days later. C57MG or RatBla cells were infected with viral supernatants, in the presence of $8 \mu \mathrm{g} / \mathrm{ml}$ of polybrene, for $2-3 \mathrm{hr}$. The next day, cells were split $1: 5$ into medium containing hygromycin B at $250 \mu \mathrm{g} / \mathrm{ml}$. Colonies were usually visible 6-8 days later. Individual colonies of RatBla infectants were picked and screened for Wnt-1 expression by immunoblotting. C57MG colonies were pooled, and parallel plates were used for protein analysis by immunoblotting and for autocrine transformation assays.

\section{Protein analysis and morphology assays}

C57MG cell lines and clones of RatBla cells were screened for Wnt-1 protein expression by immunobloting using chemiluminescent detection as described previously (Mason et al. 1992). For pulse-chase analysis, subconfluent $60-\mathrm{mm}$ dishes of RatB1a cells were labeled with $1 \mathrm{ml}$ of $0.4 \mathrm{mCi} / \mathrm{ml}\left[{ }^{35}\right.$ S $]$ cysteine (ICN) in DME (minus cysteine) for $1 \mathrm{hr}$ at $37^{\circ} \mathrm{C}$, and chased in $1 \mathrm{ml}$ of DME with $10 \%$ FBS and $1 \mathrm{~mm}$ suramin (FBA Pharmaceuticals, CT) for $4 \mathrm{hr}$. The medium was removed and cleared in an Eppendorf microcentrifuge for $10 \mathrm{~min}$ before addition of anti-Wnt antibody. Cell lysates were prepared by washing cells three times in cold phosphate-buffered saline (PBS), lysing them on the dish by rocking in $1 \mathrm{ml}$ of TNT buffer $(20 \mathrm{~mm}$ Tris at $\mathrm{pH} 8.0$, $150 \mathrm{~mm} \mathrm{NaCl}, 1 \%$ Triton X-100, $1 \mathrm{~mm}$ phenylmethylsulfonyl fluoride, $20 \mu \mathrm{g} / \mathrm{ml}$ of aprotinin) for $10 \mathrm{~min}$ at $4^{\circ} \mathrm{C}$, and clearing as above. Cell lysates and medium were incubated for $3-16 \mathrm{hr}$ at $4^{\circ} \mathrm{C}$ with $1 \mu \mathrm{l}$ of anti-Wnt-1 monoclonal ascites fluid lantiWnt-1 peptide A; Brown et al. 1987), and immune complexes were precipitated with BSA-blocked protein A-Sepharose (Sigma). The beads were washed three times in cold TNT buffer, boiled in SDS loading buffer, and electrophoresed on $10 \%$ polyacrylamide gels. The gel was fixed, soaked in Enhance (Amersham), dried and exposed to X-ray film (Hyperfilm, Amersham).

To best judge the morphology of the C57MG cell lines expressing Wnt-l and the chimeras, the medium was removed just before the cells reached confluence and replaced with $\mathrm{HB}-\mathrm{CHO}$ (Hana Biologics, Irvine CA), a defined medium that enhances differences in morphology by flattening out the parental C57MG cells (Mason et al. 1992). For paracrine assays, $\sim 5 \times 10^{5}$ RatBla cells were plated together with an equal number of C57MG cells in 60-mm dishes; the following day, the medium was changed to HB-CHO. Cells were photographed 2 days later with Polaroid film and a Nikon TMS inverted microscope at a magnification of $200 \times$.

\section{Flow cytometry}

RatBla cells were removed from $60-\mathrm{mm}$ plates by treatment with enzyme-free cell dissociation buffer (GIBCO) as recommended by the vendor. Cells were resuspended in $100 \mu$ of PBS containing $2 \% \mathrm{FBS}$ (staining buffer) and incubated with $10 \mu \mathrm{l}$ of fluorescein isothiocyanate-labeled Leu2a (anti-CD8) or phycoerythrin-labeled Leu3a (anti-CD4) (Becton-Dickinson) for 30-45 min on ice. The cells were washed twice in staining buffer, resuspended in staining buffer containing $1 \mu \mathrm{g} / \mathrm{ml}$ of propidium iodide, filtered though a $35-\mu \mathrm{m}$ nylon mesh, and analyzed in a fluorescence-activated cell scanner equipped with Lysis II software (Becton-Dickinson). Only viable cells (those that did not take up propidium iodide) were included in the analysis.

\section{Immunofluorescence}

Cells were plated on coverslips that had been precoated with fibronectin (covered in $100 \mu \mathrm{l}$ of $0.1 \mathrm{mg} / \mathrm{ml}$ fibronectin, airdried, and rehydrated) at low density. The next day, samples were washed twice in cold PBS containing $0.2 \%$ gelatin and $0.1 \%$ sodium azide (IF buffer), incubated with primary antibody (1:200, anti-Wnt-1 monoclonal ascites or $5 \mu \mathrm{g} / \mathrm{ml}$ of purified OKT8) in IF buffer for $20 \mathrm{~min}$ on ice, washed, incubated with secondary antibody $11: 200$ Texas Red-conjugated anti-mouse IgG; Accurate Antibodies), washed, fixed in $0.37 \%$ paraformaldehyde for $10 \mathrm{~min}$ on ice, and mounted in glycerol containing 
$3 \%$ n-propyl gallate. Samples were examined using a Leitz Orthoplan 2 inverted microscope and photographed with Tri-X black and white film (at ASA 800 ) at a magnification of $\sim 500 \times$. Exposure times for samples stained with anti-Wnt-l antibody were $\sim 1-1.5 \mathrm{~min}$.

\section{Xenopus embryo injections}

Capped RNAs were transcribed using SP6 RNA polymerase (Promega) and the cap analog $\mathrm{m}^{7} \mathrm{GpppG}$ (Pharmacia), as described by the supplier. Unincorporated nucleotides were removed on a G-50 column, and the RNAs were precipitated with ammonium acetate and ethanol, resuspended in DEPC-treated water, and quantitated spectrophotometrically. The integrity and concentration of the RNAs were confirmed by agarose gel electrophoresis and staining with ethidium bromide. Samples were then diluted so that the desired dose was contained in $25 \mathrm{nl}$.

$X$. laevis frogs were maintained, and embryos were obtained, fertilized, and injected essentially as described (Moon and Christian 1989). Embryos were injected with $25 \mathrm{nl}$ of RNA at the two-cell stage ( $\sim 90 \mathrm{~min}$ after fertilization at $\left.19^{\circ} \mathrm{C}\right)$, in the vegetal half of one blastomere, using an automatic injector. Neurula (stage 19-20) and tailbud (stage 28) stage embryos were examined for evidence of axial duplications and photographed. In cases where two independent clones of a particular construct were tested, no significant differences were observed and the results were combined for Table 2 .

\section{Acknowledgments}

We thank Dave Lenardo for constructing Wnt $\Delta$ CD4, Brian Irving for $\mathrm{CD} 8 \zeta$ and purified OKT8, John Murphy for pLHTCX, Enrique Amaya for pSP36T, and Bob Finney for RatB la cells. For assistance with Xenopus embryo manipulation, we thank Noriyuki Kinoshita and Enrique Amaya in the Kirschner laboratory. We are grateful for assistance from Ken Kaplan for immunofluorescence and from Paul Dazin (UCSF cell sorting lab, Howard Hughes Medical Institute) for flow cytometry. Finally, thanks go to members of the Wnt group for their advice and to them and Roel Nusse for comments on the manuscript. N.P. is the recipient of a Centennial Fellowship from the Medical Research Council of Canada. J.K. was an American Cancer Society (California division) Senior Fellow, and H.E.V. is an American Cancer Society Research Professor. This work was supported by a grant from the National Institutes of Health (CA 39832).

The publication costs of this article were defrayed in part by payment of page charges. This article must therefore be hereby marked "advertisement" in accordance with 18 USC section 1734 solely to indicate this fact.

\section{References}

Baker, N.E. 1988. Embryonic and imaginal requirements for wingless, a segment-polarity gene in Drosophila. Dev. Biol. 125: $96-108$.

Blasband, A., B. Schryver, and J. Papkoff. 1992. The biochemical properties and transforming potential of human Wnt-2 are similar to Wnt-1. Oncogene 7: 153-161.

Brachmann, R., P.B. Lindquist, M. Nagashima, W. Kohr, T. Lipari, M. Napier, and R. Derynck. 1989. Transmembrane TGF- $\alpha$ precursors activate EGF/TGF- $\alpha$ receptors. Cell 56: 691-700.

Bradley, R.S. and A.M.C. Brown. 1990. The proto-oncogene int -1 encodes a secreted protein associated with the extra- cellular matrix. EMBO I. 9: 1569-1575.

Brannan, C.I., S.D. Lyman, D.E. Williams, J. Eisenman, D.M. Anderson, D. Cosman, M.A. Bedell, N.A. Jenkins, and N.G. Copeland. 1991. Steel-Dickie mutation encodes a c-kit ligand lacking transmembrane and cytoplasmic domains. Proc. Natl. Acad. Sci. 88: 4671-4674.

Bringman, T.S., P.B. Lindquist, and R. Derynck. 1987. Different transforming growth factor- $\alpha$ species are derived from a glycosylated and palmitoylated transmembrane precursor. Cell 48: 429-440.

Brown, A.M.C., R.S. Wildin, T.J. Prendergast, and H.E. Varmus. 1986. A retrovirus vector expressing the putative mammary oncogene int 1 causes partial transformation of a mammary epithelial cell line. Cell 46: 1001-1009.

Brown, A.M.C., J. Papkoff, Y.K. T. Fung, G.M. Shackleford, and H.E. Varmus. 1987. Identification of protein products encoded by the proto-oncogene int-1. Mol. Cell. Biol. 7: 39713977.

Cagan, R.L., H. Kramer, A.C. Hart, and S.L. Zipursky. 1992. The bride of sevenless and sevenless interaction: Internalization of a transmembrane ligand. Cell 69: 393-399.

Chakrabarti, A., G. Matthews, A. Colman, and L. Dale. 1992. Secretory and inductive properties of Drosophila wingless protein in Xenopus oocytes and embryos. Development 115: 355-369.

Cumberledge, S. and M.A. Krasnow. 1993. Intercellular signalling in Drosophila segment formation reconstructed in vitro. Nature 363: 549-552.

DiNardo, S., E. Sher, J. Heemskerk-Jongens, J.A. Kassis, and P.H. O'Farrell. 1988. Two-tiered regulation of spatially patterned engrailed gene expression during Drosophila embryogenesis. Nature 332: 604-609.

Dobashi, Y. and D.F. Stern. 1991. Membrane-anchored forms of EGF stimulate focus formation and intercellular communication. Oncogene 6: 1151-1159.

Finney, R.E. and J.M. Bishop. 1993. Predisposition to neoplasmic transformation caused by gene replacement of $\mathrm{H}$-ras 1 . Science 260: 1524-1527.

Flanagan, J.G. and P. Leder. 1990. The kit ligand: A cell surface molecule altered in steel mutant fibroblasts. Cell 63: 185194.

Flanagan, J.G., D.C. Chan, and P. Leder. 1991. Transmembrane form of the kit ligand growth factor is determined by alternative splicing and is missing in the $\mathrm{Sl}^{d}$ mutant. Cell 64: 1025-1035.

Fung, Y.-K.T., G.M. Shackleford, A.M.C. Brown, G.S. Sanders, and H.E. Varmus. 1985. Nucleotide sequence and expression in vitro of cDNA derived from mRNA of int-1, a provirally activated mouse mammary oncogene. Mol. Cell. Biol. 5: 3337-3344.

González, F., L. Swales, A. Bejsovec, H. Skaer, and A. Martinez Arias. 1991. Secretion and movement of wingless protein in the epidermis of the Drosophila embryo. Mech. Dev. 35: 4354.

Heemskerk, J., S. DiNardo, R. Kostriken, and P.H. O'Farrell. 1991. Multiple modes of engrailed regulation in the progression towards cell fate determination. Nature 352: 404-410.

Ingham, P.W. and A. Hidalgo. 1993. Regulation of wingless transcription in the Drosophila embryo. Development 117: 283291.

Irving, B.A. and A. Weiss. 1991. The cytoplasmic domain of the $T$-cell receptor $\zeta$ chain is sufficient to couple to receptorassociated signal transduction pathways. Cell 64: 891-901.

Janeway, C.A. 1992. The $\mathrm{T}$ cell receptor as a multicomponent signaling machine: CD4/CD8 coreceptors and CD45 in $T$ cell activation. Annu. Rev. Immunol. 10: 645-674. 
Jue, S.F., R.S. Bradley, J.A. Rudnicki, H.E. Varmus, and A.M.C. Brown. 1992. The mouse Wnt-1 gene can act via a paracrine mechanism in transformation of mammary epithelial cells. Mol. Cell. Biol. 12: 321-328.

Kimelman, D., J.L. Christian, and R.T. Moon. 1992. Synergistic principles of development: overlapping patterning systems in Xenopus mesoderm induction. Development 116: 1-9.

Kitajewski, J., J.O. Mason, and H.E. Varmus. 1992. Interaction of Wnt-1 proteins with the binding protein, BiP. Mol. Cell. Biol. 12: 784-790.

Krämer, H., R.L. Cagan, and S.L. Zipursky. 1991. Interaction of bride of sevenless membrane-bound ligand and the sevenless tyrosine-kinase receptor. Nature 352: 207-212.

Krieg, P.A. and D.A. Melton. 1984. Functional messenger RNAs are produced by SP6 in vitro transcription of cloned cDNAs. Nucleic Acids Res. 12: 7057-7070.

Kriegler, M., C. Perez, K. DeFay, I. Albert, and S.D. Lu. 1988. A novel form of TNF/cachetin is a cell surface cytotoxic transmembrane protein: Ramifications for the complex physiol ogy of TNF. Cell 53: 45-53.

Kunkel, T.A., J.D. Roberts, and R.A. Zakour. 1987. Rapid and efficient site-specific mutagenesis without phenotypic selection. Methods Enzymol. 154: 367-403.

Lupton, S.D., L.L. Brunton, V.A. Kalberg, and R.W. Overell. 1991. Dominant positive and negative selection using a hygromycin phosphotransferase-thymidine kinase fusion gene. Mol. Cell. Biol. 11: 3374-3378.

Martinez Arias, A., N.E. Baker, and P.W. Ingham. 1988. Role of segment polarity genes in the definition and maintenance of cell states in the Drosophila embryo. Development 103: 157-170.

Mason, J.O., J. Kitajewski, and H.E. Varmus. 1992. Mutational analysis of mouse Wnt-1 identifies two temperature-sensitive alleles and attributes of Wnt-1 protein essential for transformation of a mammary cell line. Mol. Biol. Cell. 3: $521-533$.

McMahon, A.P. and A. Bradley. 1990. The Wnt-1 (int-1) protooncogene is required for development of a large region of the mouse brain. Cell 62: 1073-1085.

McMahon, A.P. and R.T. Moon. 1989. Ectopic expression of the proto-oncogene int-1 in Xenopus embryos leads to duplication of the embryonic axis. Cell 58: 1075-1084.

Miller, A.D. and C. Buttimore. 1986. Redesign of retrovirus packaging cell lines to avoid recombination leading to helper virus production. Mol. Cell. Biol. 6: 2895-2902.

Miller, A.D. and G.J. Rosman. 1989. Improved retroviral vectors for gene transfer and expression. BioTechniques 7:980-990.

Moon, R.T. 1993. In pursuit of the functions of the Wnt family of developmental regulators: Insights from Xenopus laevis. BioEssays 15: 91-97.

Moon, R.T. and J.L. Christian. 1989. Microinjection and expression of synthetic mRNAs in Xenopus embryos. Technique 1: 76-89.

Morata, G. and P.A. Lawrence. 1977. The development of wingless, a homeotic mutation of Drosophila. Dev. Biol. 56: 227240.

Mroczkowski, B., M. Reich, J. Whittaker, G.I. Bell, and S. Cohen. 1988. Expression of human epidermal growth factor precursor cDNA in transfected mouse NIH 3 T3 cells. Proc. Natl. Acad. Sci. 85: 126-130.

Mroczkowski, B., M. Reich, K. Chen, G.I. Bell, and S. Cohen. 1989. Recombinant human epidermal growth factor precursor is a glycosylated membrane protein with biological activity. Mol. Cell. Biol. 9: 2771-2778.

Noordermeer, J., P. Johnston, F. Rijsewijk, R. Nusse, and P.A. Lawrence. 1992. The consequences of ubiquitous expression of the wingless gene in the Drosophila embryo. Development 116: 711-719.

Nusse, R. and H. Varmus. 1982. Many tumors induced by the mouse mammary tumor vinus contain a provirus integrated in the same region of the host genome. Cell 31: 99-109.

1992. Wnt genes. Cell 69: 1073-1087.

Nusse, R. A. van Ooyen, D. Cox, Y.K.T. Fung, and H. Varmus. 1984. Mode of proviral activation of a putative mammary oncogene (int-1) on mouse chromosome 15. Nature 307: $131-136$

Papkoff, J. and B. Schryver. 1990. Secreted int-1 protein is associated with the cell surface. Mol. Cell. Biol. 10: 2723-2730.

Papkoff, J., A.M.C. Brown, and H.E. Varmus. 1987. The int-1 proto-oncogene products are glycoproteins that appear to enter the secretory pathway. Mol. Cell. Biol. 7: 3978-3984.

Pelham, H.R.B. 1990. The retention signal for soluble proteins of the endoplasmic reticulum. Trends Biochem. Sci. 15: 483-486.

Perez, C., I. Albert, K. DeFay, N. Zachariades, L. Gooding, and M. Kriegler. 1990. A nonsecretable cell surface mutant of tumor necrosis factor (TNF) kills by cell-to-cell contact. Cell 63: 251-258.

Rathjen, P.D., S. Toth, A. Willis, J.K. Heath, and A.G. Smith. 1990. Differentiation inhibiting activity is produced in matrix-associated and diffusible forms that are generated by alternate promoter usage. Cell 62: 1105-1114.

Rebay, I., R.J. Fleming, R.G. Fehon, L. Cherbas, P. Cherbas, and S. Artavanis-Tsakonas. 1991. Specific EGF repeats of Notch mediate interactions with Delta and Serrate: Implications for Notch as a multifunctional receptor. Cell 67: 687-699.

Rettenmier, C.W. and M.F. Roussel. 1988. Differential processing of colony-stimulating factor 1 precursors encoded by two human cDNAs. Mol. Cell. Biol. 8: 5026-5034.

Rijsewijk, F., L. van Deemter, E. Wagenaar, A. Sonnenberg, and R. Nusse. 1987. Transfection of the int-1 mammary oncogene in cuboidal RAC mammary cell line results in morphological transformation and tumorigenicity. EMBO I. 6: 127131.

Sambrook, J., E.F. Fritsch, and T. Maniatis. 1989. Molecular cloning: A laboratory manual, 2nd ed. Cold Spring Harbor Laboratory Press, Cold Spring Harbor, New York.

Shackleford, G.M. and H.E. Varmus. 1987. Expression of the proto-oncogene int-1 is restricted to postmeiotic male germ cells and the neural tube of mid-gestational embryos. Cell 50: 89-95.

Shaw, A.S., K.E. Amrein, C. Hammond, D.F. Stern, B.M. Sefton, and I.K. Rose. 1989. The lck tyrosine protein kionase interacts with the cytoplasmic tail of the CD4 glycoprotein through its unique amino-terminal domain. Cell 59: 627636.

Sidow, A. 1992. Diversification of the Wnt gene family on the ancestral lineage of vertebrates. Proc. Natl. Acad. Sci. 89: 5098-5102.

Smith, W.C. and R.M. Harland. 1991. Injected XWnt-8 RNA acts early in Xenopus embryos to promote formation of a vegetal dorsalizing center. Cell 67: 753-765.

Snow, P.M., G. Keizer, J.E. Coligan, and C. Terhorst. 1984. Purification and $\mathrm{N}$-terminal amino acid sequence of the human T cell surface antigen T8. J. Immunol. 133: 2058-2066.

Sokol, S., J.L. Christian, R.T. Moon, and D.A. Melton. 1991. Injected Wnt RNA induces a complete body axis in Xenopus embryos. Cell 67: 741-752.

Struhl, G. and K. Basler. 1993. Organizing activity of wingless protein in Drosophila. Cell 72: 527-540.

Thomas, K.R. and M.R. Capecchi. 1990. Targeted disruption of the murine int-1 proto-oncogene resulting in severe abnor- 
malities in midbrain and cerebellar development. Nature 346: $847-850$

Thomas, K.R., T.S. Musci, P.E. Neumann, and M.R. Capecchi. 1991. Swaying is a mutant allele of the proto-oncogene Wnt1. Cell 67: 969-976.

Tsukamoto, A., R. Grosschedl, R.C. Guzman, T. Parslow, and H.E. Varmus. 1988. Expression of the int-1 gene in transgenic mice is associated with mammary gland hyperplasia and adenocarcinomas in male and female mice. Cell 55: 619-625.

Vaidya, A.B., E.Y. Lasfargues, J.B. Sheffield, and W.G. Coutinho. 1978. Murine mammary tumour virus (MMuTV) infection of an epithelial cell line established from C57BL/6 mouse mammary glands. Virology 90: 12-22.

van den Heuvel, M., R. Nusse, P. Johnston, and P.A. Lawrence. 1989. Distribution of the wingless gene product in Drosophila embryos: A protein involved in cell-cell communication. Cell 59: 739-749.

Weiss, A. 1993. T cell antigen receptor signal transduction: A tale of tails and cytoplasmic protein-tyrosine kinases. Cell 73: 209-212.

Wen, D., E. Peles, R. Cupples, S.V. Suggs, S.S. Bacus, Y. Luo, G. Trail, S. Hu, S.M. Silbiger, R.B. Levy, R.A. Koski, H.S. Lu, and Y. Yarden. 1992. Neu differentiation factor: A transmembrane glycoprotein containing an EGF domain and an immunoglobulin homology unit. Cell 69: 559-572.

Wilkinson, D.G., J.A. Bailes, and A.P. McMahon. 1987. Expression of the proto-oncogene int -1 is restricted to specific neural cells in the developing mouse embryo. Cell 50: 79-88.

Wong, S.T., L.F. Winchell, B.K. McCune, H.S. Earp, J. Teixido, J. Massague, B. Herman, and D.C. Lee. 1989. The TGF- $\alpha$ precursor expressed on the cell surface binds to the EGF receptor on adjacent cells, leading to signal transduction. Cell 56: $495-506$. 


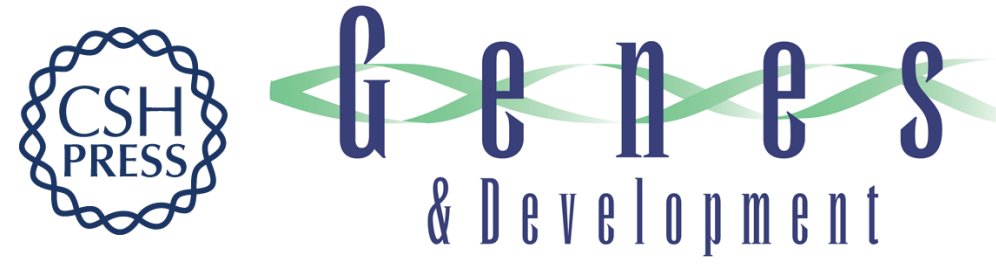

\section{Activity of Wnt-1 as a transmembrane protein.}

N T Parkin, J Kitajewski and H E Varmus

Genes Dev. 1993, 7:

Access the most recent version at doi:10.1101/gad.7.11.2181

References This article cites 69 articles, 21 of which can be accessed free at:

http://genesdev.cshlp.org/content/7/11/2181.full.html\#ref-list-1

License

Email Alerting Receive free email alerts when new articles cite this article - sign up in the box at the top Service right corner of the article or click here.

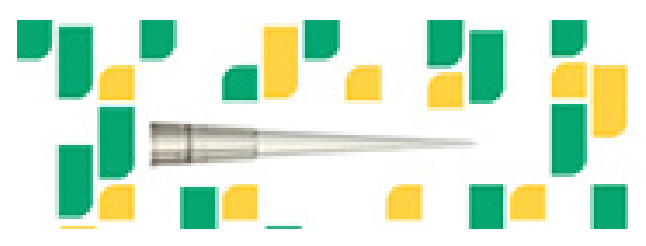

Focused on your science.

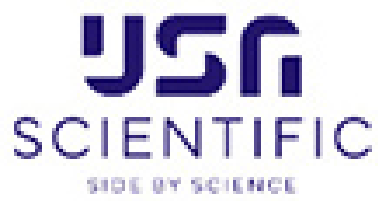

Copyright @ Cold Spring Harbor Laboratory Press 